\title{
Reliability and validity of the neonatal feeding assessment scale (NFAS) for the early identification of dysphagia in moderate to late preterm neonates
}

\author{
Mari Viviers ${ }^{1,2}$, Alta Kritzinger ${ }^{1}$, Marien Graham ${ }^{3}$
}

1. University of Pretoria, Department of Speech Language Therapy and Audiology.

2. NHS Guys and St Thomas' Foundation Trust, Evelina London Children's Hospital.

3. University of Pretoria, Department of Statistics.

\begin{abstract}
:
Background: A clinical feeding assessment instrument to assist with early identification of oropharyngeal dysphagia (OPD) in neonates was developed.

Objective: To investigate the validity and reliability of the Neonatal Feeding Assessment Scale (NFAS) in comparison to the modified barium swallow study (MBSS) as gold standard.

Method: A within-subject design was implemented. A group of 48 late premature neonates (mean gestational age 35.5 weeks) were sampled in the neonatal intensive care unit.

Results: The NFAS consists of six subsections, including physiological stability, infant state, stress cues, screening of muscle tone and control, oral peripheral examination and feeding/swallowing assessment. 93\% of participants (14/15) received confirmatory diagnosis of OPD on MBSS. The NFAS presented with high sensitivity $(78.6 \%)$ and specificity $(88.2 \%)$ scores. The positive predictive value was $78.6 \%$. Subsequently the accuracy of the NFAS to identify the presence of OPD accurately was $85.4 \%$ when compared to MBSS. Inter-rater reliability was determined on $35 \%$ of the sample. The inter-rater agreement on overall instrument outcome was substantial beyond chance.

Conclusion: The NFAS may be of use to clinicians to support the early identification of OPD in this population, especially in resource constrained settings working without access to MBSS and to reach under served neonates.

Keywords: Inter-rater reliability, modified barium swallow study, Neonatal Feeding Assessment Scale (NFAS), oropharyngeal dysphagia diagnosis, validity.

DOI: https://dx.doi.org/10.4314/ahs.v19i3.47

Cite as: Viviers $M$, Kritzinger $A$, Graham $M$. Reliability and validity of the neonatal feeding assessment scale (NFAS) for the early identification of dysphagia in moderate to late preterm neonates. Afri Health Sci. 2019;19(3): 2718-2727. https://dx.doi. org/10.4314/abs.v19i3.47
\end{abstract}

\section{Introduction}

Neonatal dysphagia is a complex condition and is caused by a variety of underlying etiologies. ${ }^{1,2}$ The condition is associated with multiple medical problems such as bronchopulmonary dysplasia (BPD), congenital anomalies of the heart and gut, necrotizing enterocolitis, gastro-esophageal reflux disease (GERD), prematurity, low

\section{Corresponding author: \\ Mari Viviers, University of Pretoria, Department of Speech Language Therapy and Audiology. NHS Guys and St Thomas' Foundation Trust, Evelina London Children's Hospital. \\ Email: marimviviers@gmail.com, mmdebeer@hotmail.com}

birth weight (LBW) and small-for-gestational age (SGA). ${ }^{1}$ Clinicians should accordingly consider the complex interplay between various medical conditions along with associated risk factors and the evolving nature of dysphagia over time, in medically fragile neonates. An increase in the incidence of neonatal dysphagia in Africa and globally, could be attributed to a variety of factors such as improved survival rates of infants with medically complex conditions, improved identification of feeding and swallowing difficulties, expansion of the medical field of speech-language pathology within the neonatal intensive care unit (NICU), improved diagnostic ability with modified barium swallow studies (MBSS) and increase in skilled clinicians managing feeding difficulties in highrisk neonates. ${ }^{1-3}$ In the case of premature neonates, the immature digestive and respiratory systems of the neonate contribute to immature feeding skills, while essential

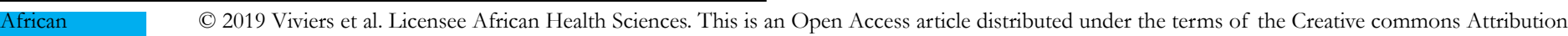

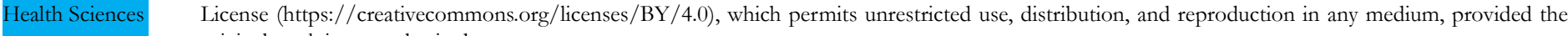
original work is properly cited. 
medical management and comorbidities further contribute to the interruption of feeding development. ${ }^{1,4}$ Since it is possible to effectively bypass the oral feeding route in premature neonates by means of enteral and tube feeding, OPD may be a hidden problem and only receive attention once these neonates have difficulty transitioning to oral feeding when medically stable.

Neonates with OPD are at risk of a compromised nutritional status, slow weight gain, regulatory problems, later behavioural difficulties and developmental delays. ${ }^{6-9}$ OPD subsequently leads to increased healthcare costs and length of hospital stay. ${ }^{1,10}$ When OPD is not identified early via valid and effective assessment, it may be difficult to utilize available resources optimally in the presence of constraints in developing countries. Healthcare funding and physical as well as human resources should be utilized fully during assessment and treatment of neonatal dysphagia to ensure timely, cost-effective services. As such there is a need for valid and reliable assessments in the area of paediatric feeding difficulties.

In African countries where there may be limited access to MBSS or where a neonate is not medically stable to undergo instrumental assessment procedures, reliable clinical identification of OPD is required to provide effective and timely intervention. In turn, early identification and intervention may increase oral feeding opportunities, and decrease cost related to long-term medical and rehabilitation services. A valid instrument to address early identification of OPD remains unavailable for the neonatal population. ${ }^{3}$ Development of the Neonatal Feeding Assessment Scale (NFAS) ${ }^{16}$ began in response to the need for an efficient, objective, and clinically valid means, to reliably identify OPD in high-risk neonates.

Consequently, the research question for the current study was: 'Is the NFAS a valid and reliable assessment instrument for the early identification of OPD in premature neonates?

\section{Methods \\ Objectives}

The objectives were a) to describe the feeding and swallowing assessment outcomes of the participants on the MBSS and the NFAS; b) to determine criterion validity regarding the psychometric properties of the NFAS, namely specificity, sensitivity, accuracy and predictive values; and, c) to determine inter-rater reliability of te NFAS.

\section{Design}

A comparative within-subject design ${ }^{18}$, where all participants were exposed to the same assessment procedures, was used to determine the psychometric properties of the NFAS on a group of high-risk neonates. The NFAS and MBSS results were compared concerning outcome for accurate identification of the presence of OPD.

\section{Participants}

Forty eight neonates admitted to a 29 bed NICU at a tertiary academic hospital in Gauteng, South Africa were purposely sampled. The inclusion criteria were: reported feeding difficulties, age range from 32 weeks gestational age (GA) to full term, medically stable for clinical and MBSS assessment as declared by the treating physician. Verbal or written informed consent was obtained from all the mothers. The information brochure and informed consent were available in three official languages of South Africa (Afrikaans, English and Setswana).

Table 1 indicated that the majority of participants presented with a $>10$ day duration of stay in the NICU $(91.7 \%, \mathrm{n}=44), \mathrm{LBW}(85.4 \%, \mathrm{n}=41)$ and late preterm birth $(64.6 \%, n=31$; mean GA of 35.58 weeks). Additional data from the case history and review of medical records highlighted numerous risk factors associated with neonatal feeding difficulties and dysphagia. ${ }^{1,14}$ These risks were: hyperbillirubinemia $(62.5 \%, \mathrm{n}=30)$, delayed introduction of oral feeding $(60.4 \%, n=29)$, respiratory distress syndrome (RDS) $(47.9 \%, \mathrm{n}=23)$ and exposure to HIV in utero or during birth $(10.4 \%, n=5)$.

\section{Materials}

Medical records and parental interviews were used to obtain additional information. The NFAS ${ }^{16}$ and a MBSS checklist was developed for use in this study. ${ }^{19}$ The philosophy underlying the NFAS and a detailed description of the instrument is available in previously published articles.

\section{NFAS sections and scoring}

The NFAS consists of six sections to support the clinical assessment of neonatal feeding skills to identify the presence or absence of OPD. ${ }^{19}$ The six sections of the NFAS were scored using a binary system. ${ }^{19}$ The different items 
are clear descriptions of observable behaviours, thereby prompting the clinician about behaviours to evaluate see Appendix A for examples of items included in the NFAS. The scoring instructions were provided in each section to reach a composite score when the NFAS was completed. ${ }^{19}$ The composite score indicated if OPD was present or absent. ${ }^{19}$ Clear administration guidelines are provided for all items. ${ }^{19}$ The sections of the NFAS is depicted in Figure 1.

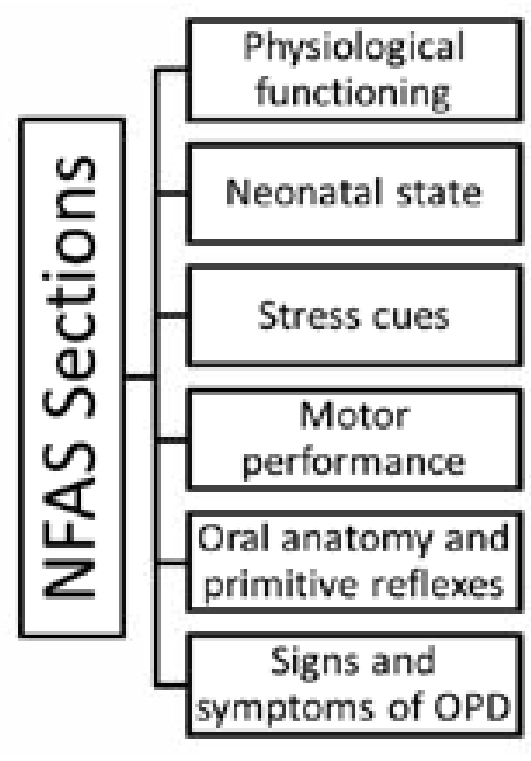

Figure 1: Sections of the NFAS assessment instrument

\section{MBSS material and apparatus}

The MBSS checklist developed for this study allowed the raters to indicate which stage of swallowing -oral, pharyngeal, and/or oesophageal- was affected. ${ }^{26,30,37}$ The rater also indicated presence or absence of penetration or aspiration during the pharyngeal stage. In this study dysphagia was defined broader than only the presence of penetration or aspiration. A recent more comprehensive definition of dysphagia by Dodrill and Gasa ${ }^{43}$ was adopted for diagnosis of OPD in this study. The aforementioned authors defined dysphagia as "any disruption to the swallow sequence that result in a compromise of the safety, efficiency, or adequacy of nutritional intake" (p.24). ${ }^{43}$ The two raters evaluated the MBSS for the presence of signs of dysphagia according to provided criteria. In the oral stage the following signs were indicative of oral dysphagia: excessive anterior milk loss, disorganized lingual stripping, weak sucking and incoordination of the suck-swallow-breathe (SSB) sequence. ${ }^{26,20,37,40,42}$ During the pharyngeal stage the raters considered the presence of delayed elicitation of the pharyngeal swallow response, inadequate epiglottic inversion, laryngeal penetration, tracheal aspiration, cough in response to penetration/aspiration, resultant inadequate airway protection related to incoordinated suck-swallow-breathe (SSB) sequence, inadequate vocal fold adduction, pooling in the valleculae or/and pyriform sinuses, as well as nasopharyngeal reflux as signs of pharyngeal dysphagia. $23,26,30,37,40,42-43$ In the esophageal stage the presence of GERD indicated ED.1 The MBSS was performed using a fluoroscope (SYSCO 19" version Multi DiagnostEleva FD screening machine from Philips, Netherlands) with DVD recording capabilities.

\section{Procedures}

Before any research was conducted at the tertiary hospital, clearance was obtained from the Research Ethics Committees in the Faculties of Humanities and Medicine at the university and the tertiary academic hospital in Gauteng, South Africa. Informed consent was provided by all the mothers. A parental interview was completed, followed by a breast/bottle feeding assessment (NFAS), 
and lastly a MBSS. During the MBSS procedure, a solution of barium sulphate was reconstituted by mixing the powder (E-Z-HDTM) with the $50 \mathrm{ml}$ of the mothers' expressed breast milk or recommended infant formula. The participants were fed by one of the blind raters. Fluoroscopy ran during the initial five to 10 serial swallows and when dysfunction was observed. During fluoroscopy the continuous mode with appropriate collimation was used to limit radiation exposure but still obtain the clearest view of the bolus procession. ${ }^{44-45} \mathrm{~A}$ frame capture rate of 30 frames per second was used. ${ }^{44-45}$ The maximum duration of radiation exposure was 3 minutes. ${ }^{44} \mathrm{~A}$ NUK MedicPro First choice'TM 120ml infant bottle with a MedicProTM disposable TPE Teat size 1 was used. Participants were positioned at a 45 degree upright angle with appropriate supported seating in a Tumble Forms 2 Feeder SeatTM (Jackson, MI). The MBSS was viewed in the lateral projection. The neonate's feeding and swallow- ing abilitieswere assessed with MBSS within seven days (mean $=2.25$ ) of the clinical assessment. Recorded studies were viewed and interpreted by two senior hospital speech-language pathologists blinded to the clinical outcome of the NFAS. The first view was in real time, followed by slow motion and frame-by-frame analysis after the MBSS was concluded.

\section{Data analysis}

The inter-rater reliability on the NFAS was determined using Cohen's Kappa coefficients and P Bar calculations. ${ }^{17}$ As in other clinical studies of instrument development, a Kappa value of greater than 0.41 was considered a minimal reliability criterion and a P Bar value of $0.50 .17,46$ Criterion validity of the NFAS outcome in comparison to the diagnosis obtained on MBSS was determined by calculating sensitivity, specificity, positive and negative predictive value indicators and accuracy scores. ${ }^{17}$

Table 1 Participant description $(n=48)$

\begin{tabular}{|lcccc|} 
Participant characteristics & Mean & Median & Mode & $\begin{array}{c}\text { Standard } \\
\text { Deviation (SD) }\end{array}$ \\
\hline Gestational age at birth (weeks) & 35.58 & 35.0 & 34 & 3.06 \\
\hline Birth weight (grams) & 2118 & 1960 & 1400 & 718.5 \\
Corrected age at assessment (weeks) & 26.96 & 36.85 & 35.00 & 2.92 \\
Number of days in NICU & 9.52 & 7.00 & 4 & 8.71 \\
\hline
\end{tabular}

\section{Results}

\section{NFAS results}

OPD was identified in fifteen participants $(31.3 \%)$ and 33 participants $(68.7 \%)$ did not meet the criteria to be

Table 2 Comparative assessment results $(n=48)$ identified with OPD on the NFAS (Table 2). Signs and reported symptoms of oral and possible pharyngeal dysphagia could be documented on the NFAS, but pharyngeal and esophageal stage difficulties could not be confirmed without instrumental assessment.

\begin{tabular}{lcc}
\hline \multicolumn{1}{c}{ Assessment instruments } & OPD present & OPD absent \\
\hline 1. NFAS & $31.3 \%(\mathrm{n}=15)$ & $68.7 \%(\mathrm{n}=33)$ \\
2. MBSS & $29.2 \%(\mathrm{n}=14)$ & $70.8 \%(\mathrm{n}=34)$ \\
$\begin{array}{l}\text { Total agreement between assessment } \\
\text { instruments }\end{array}$ & $93.3 \%$ & $97.1 \%$ \\
\hline
\end{tabular}

\section{MBSS results}

The MBSS results and the NFAS results are presented together in Table 2 to enable comparison between the results.

In the MBSS sample, 14 of the neonates presented with
OPD $(29.2 \%)$ and 25 presented with ED. Nine of the participants presented with no dysphagia. Co-occurrence of OPD and ED was present in $28.5 \%(n=4)$ of the participants. The total agreement between the NFAS and MBSS on accurate identification of OPD was $93.3 \%$. 


\section{Comparative results of the NFAS and the MBSS Validity}

Table 3 provides the data related to the criterion validity of the NFAS.

As evident from Table 3, a sensitivity score (true positive) of $78.6 \%$ was obtained with specificity (true negative) determined to be $88.2 \%$ for the NFAS. The data demonstrated that one false positive $(11.8 \%)$ was rendered by the NFAS, which could possibly be ascribed to the set inclusion criteria. The predictive ability of the instrument incidentally achieved exact agreement with the sensitivity and specificity. The positive predictive value was 78.6\% and the negative predictive value was $88.2 \%$. The subsequent accuracy of the NFAS was $85.4 \%$ when compared to the MBSS outcome. The NFAS therefore presents with high sensitivity, specificity, good predictive ability and good accuracy for identification of OPD during clinical assessment. ${ }^{17}$

Table 3 Comparison between the gold standard (MBSS) and the NFAS (n=48)

\begin{tabular}{|c|c|c|c|c|}
\hline & & & & \multirow[b]{3}{*}{$\begin{array}{l}\text { Total neonates } \\
\text { in which OPD } \\
\text { is } \\
\text { present/absent } \\
\text { on NFAS }\end{array}$} \\
\hline & & \multicolumn{2}{|c|}{ Outcome of MBSS $(\mathrm{n}=48)$} & \\
\hline & & OPD present & OPD absent & \\
\hline \multirow{8}{*}{$\begin{array}{l}\text { Outcome of NFAS } \\
(\mathrm{n}=48)\end{array}$} & & True Positive (TP) & $\overline{\text { False Positive (FP) }}$ & \\
\hline & OPD present & 11 & 4 & 15 \\
\hline & $\% N F A S$ & $73.3 \%$ & $26.7 \%$ & $100 \%$ \\
\hline & $\% M B S S$ & $78.6 \% *$ & $11.8 \%$ & $31.3 \%$ \\
\hline & & False Negative (FN) & True Negative (TN) & \\
\hline & OPD absent & 3 & 30 & 33 \\
\hline & $\% N F A S$ & $9.1 \%$ & $90.9 \%$ & $100 \%$ \\
\hline & $\% M B S S$ & $21.4 \%$ & $88.2 \% *$ & $68.8 \%$ \\
\hline \multirow{3}{*}{$\begin{array}{l}\text { Total neonates in } \\
\text { which OPD is } \\
\text { present/absent on } \\
\text { MBSS }\end{array}$} & Count & 14 & 34 & 48 \\
\hline & $\% N F A S$ & $29.2 \%$ & $70.8 \%$ & $100 \%$ \\
\hline & $\% M B S S$ & $100 \%$ & $100 \%$ & $100 \%$ \\
\hline
\end{tabular}

\section{Reliability}

Inter-rater reliability was determined for each section of the NFAS and for diagnosis for $35.0 \%$ of the sample, utilizing two raters. The results of each section and overall agreement on diagnostic outcome together with the asymptotic standard error (ASE) are depicted in Table 4. According to Table 4 results of three of the five sec- tions on the NFAS reached a minimally acceptable level of agreement between two independent raters. However, four of the five sections had an acceptable P Bar level of agreement. Substantial agreement beyond chance $(0.586$ P Bar) was achieved between the two raters on the identification of OPD with the NFAS resulting in an acceptable ASE of $0.211 .^{17}$ 
Table 4 Inter-rater reliability for each section and overall diagnostic outcome of the NFAS (n=17)

\begin{tabular}{|c|c|c|c|c|c|}
\hline NFAS section & Kappa & Level of agreement & P Bar & $\begin{array}{l}\text { Overall agreement } \\
\text { between raters } \\
(\%)\end{array}$ & $\begin{array}{c}\text { Asymptotic } \\
\text { Standard Error } \\
\text { (ASE) }\end{array}$ \\
\hline $\begin{array}{l}\text { A \& B } \\
\text { A Physiological } \\
\text { subsystem functioning } \\
\text { B State of alertness } \\
\text { during feeding }\end{array}$ & 0.062 & $\begin{array}{l}\text { Poor/chance } \\
\text { agreement }\end{array}$ & 0.764 & $76.4 \%$ agreement & 0.044 \\
\hline $\begin{array}{l}\text { C Stress cues during } \\
\text { feeding }\end{array}$ & 0.212 & Slight agreement & 0.176 & $17.6 \%$ agreement & 0.141 \\
\hline $\begin{array}{l}\text { D General movement \& } \\
\text { muscle tone screening }\end{array}$ & 1.00 & Perfect agreement & 1.00 & $100 \%$ agreement & 0.000 \\
\hline $\begin{array}{l}\text { E Oral peripheral } \\
\text { evaluation }\end{array}$ & 0.628 & $\begin{array}{c}\text { Good } \\
\text { agreement/Good } \\
\text { agreement beyond } \\
\text { chance }\end{array}$ & 0.650 & $65 \%$ agreement & 0.193 \\
\hline $\begin{array}{l}\text { F Clinical feeding \& } \\
\text { swallowing evaluation }\end{array}$ & 0.485 & $\begin{array}{c}\text { Fair agreement/Good } \\
\text { agreement beyond } \\
\text { chance }\end{array}$ & 0.529 & $52.9 \%$ agreement & 0.222 \\
\hline $\begin{array}{l}\text { Total (Diagnostic } \\
\text { outcome of NFAS) }\end{array}$ & 0.598 & $\begin{array}{c}\text { Substantial } \\
\text { agreement }\end{array}$ & 0.586 & $58.6 \%$ agreement & 0.211 \\
\hline
\end{tabular}

Table 5 Inter-rater reliability for each section and overall diagnostic outcome of the NFAS (n=17)

\begin{tabular}{|c|c|c|c|c|c|}
\hline NFAS section & Kappa & Level of agreement & P Bar & $\begin{array}{l}\text { Overall agreement } \\
\text { between raters } \\
(\%)\end{array}$ & $\begin{array}{c}\text { Asymptotic } \\
\text { Standard Error } \\
\text { (ASE) }\end{array}$ \\
\hline $\begin{array}{l}\text { A \& B } \\
\text { A Physiological } \\
\text { subsystem functioning } \\
\text { B State of alertness } \\
\text { during feeding }\end{array}$ & 0.062 & $\begin{array}{c}\text { Poor/chance } \\
\text { agreement }\end{array}$ & 0.764 & $76.4 \%$ agreement & 0.044 \\
\hline $\begin{array}{l}\text { C Stress cues during } \\
\text { feeding }\end{array}$ & 0.212 & Slight agreement & 0.176 & $17.6 \%$ agreement & 0.141 \\
\hline $\begin{array}{l}\text { D General movement \& } \\
\text { muscle tone screening }\end{array}$ & 1.00 & Perfect agreement & 1.00 & $100 \%$ agreement & 0.000 \\
\hline $\begin{array}{l}\text { E Oral peripheral } \\
\text { evaluation }\end{array}$ & 0.628 & $\begin{array}{c}\text { Good } \\
\text { agreement/Good } \\
\text { agreement beyond } \\
\text { chance }\end{array}$ & 0.650 & $65 \%$ agreement & 0.193 \\
\hline $\begin{array}{l}\text { F Clinical feeding \& } \\
\text { swallowing evaluation }\end{array}$ & 0.485 & $\begin{array}{c}\text { Fair agreement/Good } \\
\text { agreement beyond } \\
\text { chance }\end{array}$ & 0.529 & $52.9 \%$ agreement & 0.222 \\
\hline $\begin{array}{l}\text { Total (Diagnostic } \\
\text { outcome of NFAS) }\end{array}$ & 0.598 & $\begin{array}{r}\text { Substantial } \\
\text { agreement }\end{array}$ & 0.586 & $58.6 \%$ agreement & 0.211 \\
\hline
\end{tabular}

\section{Discussion}

The purpose of the current study was to investigate the validity and reliability of the NFAS to determine if this instrument may be useful for the early identification of OPD in premature neonates. Such early identification may decrease the economic and social burden in lower and middle income countries such as South Africa to support the overwhelmed public health care system..$^{54-55}$
Due to the possible life threatening nature of OPD in neonates, a valid clinical assessment instrument should be available to clinicians for use in the NICU. ${ }^{10}$

Validity and reliability of the NFAS in comparison to MBSS

The NFAS showed to be sensitive, specific, accurate and reliable to identify signs of OPD in the target popula- 
tion of this study. The diagnostic agreement between the NFAS and MBSS was very good17 (85.4\%), indicating that the presence of OPD can be identified with the NFAS. Co-occurrence of OPD and ED is common in premature neonates due to the immature respiratory system, uncoordinated SSB sequence, and the high prevalence of gastro-oesophageal reflux all of which impact the different stages of swallowing. ${ }^{52}$

An unexpected result was that none of the participants demonstrated penetration or aspiration during the MBSS. This surprising finding could not be explained in light of other studies' findings where different prevalence rates of penetration and/or aspiration in preterm infants were reported. A wide range of penetration/aspiration prevalence rates are reported in various studies, ranging from $17.1 \%-52.2 \% .^{53-56}$ The absence of penetration/aspiration in this sample does not rule out the presence of a continued risk of aspiration in future since the MBSS is a limited view of feeding performance at one point in time. Resilience of the airway's protective mechanism may already be evident in these late preterm neonates. Furthermore, the MBSS procedure is shorter than a typical feeding session therefore the impact of fatigue on SSB during the instrumental assessment could be limited.

A prevalence range of $25-35 \%$ for OPD in preterm and LBW neonates has been reported in some studies. ${ }^{50,57}$ The prevalence of OPD of $29.2 \%$ in this study concurs with previous research on this population.

\section{Clinical use of the NFAS}

The NFAS could be considered valid and reliable for clinical use in identifying the presence of OPD in late preterm neonates with risk factors such as HIV exposure, RDS, LBW and increased length of NICU stay. In a South African study by Pike et al., intrauterine growth restriction associated with SGA and an extended stay in the NICU was associated with OPD and ED in the same sample of participants. ${ }^{59}$ The results of the current study also found that physiologic immaturity is a contributing factor to neonatal dysphagia.

The NFAS is less invasive than MBSS and does not result in radiation exposure. The MBSS offers an observation of a discrete moment in time of the neonate's swallowing ability. Whereas the NFAS may be used more than once a day or in short succession to obtain a representative feeding profile. One of the main advantages of the NFAS is that it can be used in developing countries where less or no access to MBSS is available or while awaiting MBSS at another facility while the neonate is not medically stable to be transported. A notable feature of the NFAS is that assessment is guided by developmental supportive guidelines established for neonatal practice. ${ }^{10}$

\section{Conclusion}

The early assessment and timely management of OPD in preterm neonates is a priority since successful feeding with adequate weight gain is a discharge requirement from the NICU. ${ }^{1}$ The NFAS may offer valid early identification of OPD together with descriptive information that can support intervention planning in resource constrained settings. The NFAS enables clinicians to categorize the different signs of OPD in five categories, namely those related to physiologic instability, stress, state, level of alertness and structural and functional limitations impacting on feeding. The NFAS is likely to provide a more in-depth description of the neonate's feeding abilities than can be achieved with instrumental assessment alone. Despite the subjective nature of the NFAS, it offers a description of the signs of OPD and oral feeding competencies displayed by the neonate. Further independent research of other psychometric characteristics of the NFAS should be explored to determine test-retest reliability and responsiveness related to effect-size. This type of clinical instrument holds potential for providing a means for the early identification of OPD in settings without access to instrumental assessment, and may positively impact on service delivery to underserved high-risk neonates with OPD.

\section{Conflict of interest}

The authors declare that there is no conflict of interest.

\section{References}

1. Jadcherla S (2016) Dysphagia in the high-risk neonate: potential factors and mechanisms. American Journal of Clinical Nutrition 103(2):622-628

2. St. Pierre AE, Reelie BA, Dolan AR, Stokes RH, Duivestein JA, Holsti, L (2012) Terms used to describe pediatric videofluoroscopic feeding studies: $A$ Delphi survey. Canadian Journal of Occupational Therapy 79(3): 159-166

3. Heckathorn DE, Speyer R, Taylor J, Cordier R (2015) Systematic review: Non-instrumental swallowing and feeding assessments in paediatrics. Dysphagia Online release: $1-23$ 
4. Dodrill P (2011) Feeding difficulties in preterm neonates. ICAN: Neonate, Child, \& Adolescent Nutrition, 3: 324-331

5. Sharp WG, Jacquess DL, Morton JF, Herzinger CV (2010) Pediatric feeding disorders: A quantitative synthesis of treatment outcomes. Clinical Child and Family Psychology 13(4):348-365

6. Arvedson J, Clark H, Lazarus C, Schooling T, Frymark $\mathrm{T}$ (2010) Evidence based systematic review (EBSR): The effects of oral motor interventions on feeding and swallowing in preterm neonates. American Journal of Speech-Language Pathology 19(4):321-340

7. Gouyon JB, Iacobelli S, Ferdynus C, Bonsante F (2012) Neonate problems of late and moderate preterm neonates. Seminars in Fetal and Neonate Medicine 17(3):146-152 8. Hemmi MJ, Wolke D, Schneider S (2011) Associations between problems with crying, sleeping and/or feeding in infancy and long-term behavioural outcomes in childhood: a meta-analysis. Archives of Disease in Childhood 96:622-629

9. Schmid G, Schreier A, Meyer R, Wolke D (2010) A prospective study on the persistence of neonate crying, sleeping and feeding problems and preschool behaviour. Acta Paediatrica 99(2):286-290

10. Thoyre SM, Park J, Pados B, Hubbard C (2013) Developing a co-regulated, cue-based feeding practice: The critical role of assessment and reflection. Journal of Neonatal Nursing 19:139-148

11. European Society for Swallowing Disorders (2013) Paediatric dysphagia - position statement. http://www. myessd.org. Accessed on 3 March 2016

12. Sheppard JJ, Hochman R, Baer C (2014) The Dysphagia Disorder Survey: Validation of an assessment for swallowing and feeding function in developmental disability. Research in Developmental Disabilities 35:929-942

13. Ko MJ, Kang MJ, Ko KJ, Oki YK, Chang, HJ, Kwan JY (2011) Clinical usefulness of Schedule for Oral-Motor Assessment (SOMA) in children with dysphagia. Annals of Rehabilitation Medicine 35(4):477-484

14. Arvedson JC (2008) Assessment of pediatric dysphagia and feeding disorders: Clinical and instrumental approaches. Developmental Disabilities Research Reviews 14:118127

15. Miller CK (2009) Updates on pediatric feeding and swallowing. Current Opinion in Otolaryngology \& Head and Neck Surgery 17(3):194-199
16. Viviers M, Kritzinger A, Vinck B, Graham M. (2017) Preliminary psychometric performance of a clinical neonate feeding assessment scale. South African Journal of Communication Disorders

17. Dawson B, Trapp RG (2004) Basic and clinical biostatistics, $4^{\text {th }}$ edn. Lange Medical Books/McGraw-Hill, New York

18. Meline T (2010) A Research primer for Communication Sciences and Disorders. Allyn \& Bacon, Boston, Chapter 8

19. 1. Viviers M, Kritzinger A, Vinck, B (In press). Development of a clinical feeding assessment scale for highrisk neonates in South Africa. South African Journal of Communication Disorders

20. Als H (1982) Toward a Synactive Theory of Development: Promise for the assessment and support of the neonate individuality. Neonate Mental Health Journal, 3:229243

21. Als H, Lawhon G, Duffy FH, McAnulty GB, Gibes-Grossman R, Blickman JG (1994) Individualized developmental care for the very low-birth-weight preterm neonate: Medical and neurofunctional effects. Journal of the American Medical Association 272(11):853-858

22. Berlin KS, Davies WH, Lobato DJ, Silverman, AH (2009) A Biopsychosocial model of normative and problematic pediatric feeding. Children's Health Care 38:263-282 23. Lau C, Smith E (2011) A novel approach to assess oral feeding skills of preterm neonates. Neonatology 100(1):6470

24. Thoyre SM, Shaker CS, Pridham, KF (2005) The Early Feeding Skills Assessment for preterm neonates. Neonatal Network 24(3):7-16

25. Dieckman R, Brownstein D, Gausche-Hill M (2000) American academy of paediatrics: Pediatric education for pre-hospital professionals. Jones \& Bartlett Publishers, Boston, Chapter 2

26. Hall KD (2001) Pediatric Dysphagia: Resource Guide. Singular Thomson Learning, San Diego

27. Henning PA (2002) The Examination of the Newborn Baby. Van Schaik Publishers, Pretoria, Chapter 2

28. Hodgman JE, Hoppenbrouwers T, Cabal, LA (1993) Episodes of bradycardia during early infancy in the termborn and preterm neonate. American Journal of Disabled Children 147(9):980-984

29. Nugent JK, Keefer CH, Minear S, Johnson LC, Blanchard Y (2007) Understanding newborn behaviour 
and early relationships: The newborn behavioural observations (NBO) systems handbook. Paul H. Brookes Publishing Company, Maryland, Chapter 4

30. Arvedson JC, Brodsky L (2002) Pediatric swallowing and feeding: Assessment and management. Thomson Delmar Learning, Clifton Park

31. Brazelton TB (1973) Neonate behavioural assessment scale. Clinics in Developmental Medicine No 50. J.P. Lippincott, Phillidelphia

32. Prechtl HFR, Beintema DJ (1964) The neurological examination of the full term newborn neonate. Clinics in Developmental Medicine 12:1-49

33. Wolff PH (1959) Observations on human neonates. Psychosomatic Medicine 221:110-118

34. Clark DA (2009) Evaluation and care of the neonate. In: Ensher GL, Clark DA, Songer NS (eds) Families, neonates and young children at risk: Pathways to best practice, Paul H Brookes Publishing Co, Maryland pp 29-38 35. Van Haastert IC, De Vries LS, Helders PJM, Jongmans MJ (2006) Early gross motor development of preterm neonates according to the Alberta Neonate Motor Scale. Journal of Pediatrics 149(5):617-622

36. Bahr DC (2001) Oral motor assessment and treatment: Ages and stages. Allyn and Bacon, Boston, Chapter 3

37. Swigert NB (2010). The Source for Pediatric Dysphagia. LinguiSystems, East Moline, Chapter 2 \& 3

38. Da Costa SP, Van der Schans C (2008) The reliability of the Neonate Oral-Motor Assessment Scale. Acta Paediatrica 97:21-26

39. Darrow DH, Harley CM (1998) Evaluation of swallowing disorders in children. Otolaryngologic Clinics of North America 31(3):405-418

40. Gewolb IH, Vice FL (2006) Maturational changes in the rhythms, patterning, and coordination of respiration and swallow during feeding in preterm and term neonates. Developmental medicine \& Child Neurology 48:589-594 41. Rudolph CD, Thompson Link D (2002) Feeding disorders in neonates and children. Pediatric Clinics of North America 49(1):97-112

42. Qureshi MA, Vice FL, Taciak VL, Bosma JF, Gewolb IH (2002) Changes in rhythmic suckle feeding patterns in term neonates in the first month of life. Developmental medicine \& Child neurology 44(1):34-39

43. Dodrill P, Gasa MM (2015) Pediatric dysphagia: phys- iology, assessment and management. Annals of Nutrition and Metabolism 66(5):24-31

44. Hernanz-Schulman M, Goske MJ, Bercha IH, Strauss KJ (2011) Pause and pulse: Then steps that help manage radiation dose during pediatric fluoroscopy. Pediatric Imaging 197: 475-481

45. Scott MV, Fujii AM, Behrman RH, Dillon JE (2014) Diagnostic ionizing radiation exposure in premature infants. Journal of Perinatology 34(5):392-395

46. Landis JR, Koch GG (1977) The measurement of observer agreement for categorical data. Biometrics 33:159174

47. Lalkhen AG, McCluskey A (2008) Clinical tests: sensitivity and specificity. Continuing Education in Anaestehesia, Critical Care \& Pain 8(6):221-223

48. Portney LG, Watkins MP (2009) Foundations of clinical research - applications to practice, $3^{\text {rd }}$ edn. Pearson Prentice Hall, New Jersey, Chapter 3 \& 4

49. Zhu W, Zeng N, Wang N, (2010) Sensitivity, specificity, accuracy, associated confidence interval and ROC analysis with practical SAS® implementations. http:// www.lexjansen.com/nesug/nesug10/h1. Accessed 26 June 2015

50. DeMauro SB, Patel PR, Medoff-Cooper B, Posenscheg M, Abbasi, S (2011) Postdischarge feeding patterns in early- and late-preterm neonates. Clinical Pediatrics 50(10):957-962

51. Orenstein SR (2006) Oral, pharyngeal, and esophageal motor disorders in neonates and children. GI Motility Online doi:10.1038/gimo38

52. Fishbein M, Branham C, Fraker C, Walbert L, Cox S, Scarborough D (2013) The incidence of oropharyngeal dysphagia in neonates with GERD-like symptoms. Journal of Parenteral and Enteral Nutrition 37(5):667-673

53. Lee ACC, Katz J, Blencowe H et al (2013) National and regional estimates of term and preterm babies born small for gestational age in 138 low-income and middle-income countries in 2010. The Lancet Global Health 1(1):e26-e36

54. Mercado-Deane MG, Burton EM, Harlow SA et al (2001) Swallowing dysfunction in infants less than 1 year of age. Pediatric Radiology 31:423-428.

55. Newman LA, Keckley C, Petersen MC, Hammer A (2001) Swallowing function and medical diagnoses in infants suspected of dysphagia. Pediatrics 108(6):1-4 
56. Uhm KE, Yi SH, Chang HJ, Cheon HJ, Kwon JY (2013) Videofluoroscopic swallowing study findings in full-term and preterm infants with dysphagia. Annals of Rebabilitation Medicine 37(2):175-182

57. Zehetgruber N, Boedeker RH, Kurth R, Faas D, Zimmer KP, Heckman M (2014) Eating problems in very low birthweight children are highest during the first year and independent risk factors include duration of invasive ventilation. Acta Paediatrica 10:e424-e438

58. Crapnell TL, Rogers CE, Neil JJ, Inder TE, Woodward LJ, Pineda RG (2013) Factors associated with feed- ing difficulties in the very preterm neonate. Acta Paediatrica 102(12):e539-e545

59. Pike C, Pike M, Kritzinger A, Kruger E, Viviers, M (2016). Risk profiles of infants with oro-pharyngeal dysphagia and oesophageal dysphagia in a neonatal intensive care unit. South African Journal of Child Health 10(2):129132

60. World Health Organization (2001) International Classification of Functioning, Disability and Health (ICIDH-2). http:// www.who.int/gb/ebwha/pdf_files/ WHA54/ea5418.pdf. Accessed 10 March 2015 